\title{
Experimental Infection of Canine Peritoneal Macrophages with Visceral and Dermotropic Leishmania Strains
}

\author{
MF Madeira ${ }^{+}$, EGO Barbosa-Santos, MCA Marzochi \\ Departamento de Ciências Biológicas, Escola Nacional de Saúde Pública-Fiocruz, Rua Leopoldo Bulhões 1480, \\ 21041-210 Rio de Janeiro, RJ, Brasil
}

A study was carried out using macrophages cultured from the peritoneal exudate of dogs infected in vitro with three species of Leishmania: L. (L.) chagasi, L. (Viannia) braziliensis and L. (L.) amazonensis with the aim of investigating the growth kinetics and infectivity of these species in the host cell.

Results were expressed as the percentage of macrophages infected measured at $24 \mathrm{hr}$ intervals over six days in RPMI - 1640 culture medium at a temperature of $34-35^{\circ} \mathrm{C}$.

The findings open the possibility of using canine peritoneal cells as a model for the screenning of leishmanicide drugs and to study the pathogenesis of these species.

Key words: leishmaniasis - macrophages - dogs

Leishmanias are obligate intracellular parasites that multiply inside the cells of the mononuclear phagocytic system of vertebrate hosts. The multiplicity of species associated with transmission conditions by different vector species and host immune conditions generate variable clinical manifestations (Grimaldi Jr 1982, Marzochi \& Marzochi 1994).

Changes introduced by humans to natural environments favor the installation of non-sylvan foci, thereby leading to the involvement of various species of domestic animals, mainly canids and equids (Marzochi 1992, Marzochi \& Marzochi 1994), thus fostering the maintenance and expansion of peridomiciliary cycles.

The frequent presence of household dogs with high infection rates associated with the human disease in endemic areas for American tegumentary and visceral leishmaniasis, as well as the presence of the same genotypic pattern of the parasite circulating in human and canine populations prove the involvement of $\operatorname{dog} s$ in the peri and intradomiciliar transmission cycle of both diseases (Lopes et al. 1984, Pacheco et al. 1986). The same has been observed with regard to equine species in American tegumentary leishmaniasis (ATL) areas (Barbosa-Santos et al. 1994).

\footnotetext{
This work was supported by grants from the Oswaldo Cruz Foundation (Papes/Fiocruz 0250250378).

${ }^{+}$Corresponding author. Fax: +55-21-564.8985. E-mail: fmadeira@ensp.fiocruz.br Received 13 October 1998 Accepted 17 May 1999
}

Thus, domestic dogs have been the target of several studies and are considered an excellent model for experimental infections (Chapman et al. 1979, Pirmez et al. 1988). However data concerning the treatment of disease in dogs are limited.

In attemps to evaluate experimental treatments various models have been used in studies with these protozoa. However, in vitro cellular models offer the greatest advantages for the objective at hand concerning the in vivo system, including both simplicity and speed in obtaining results (Berman 1985).

Macrophages, described as pioneering cells surviving in axenic conditions (Carrel \& Ebeling 1922) have been used under different experimental conditions and obtained from different anatomical sites from various animal species. Such cells represent an ideal target cell population, mainly for studies of parasites from the Leishmania genus.

We have performed an in vitro investigation employing canine macrophages infected separately with three species of Leishmania in order to monitor the multiplication kinetics and possible standardization for trials using drugs with leishmanicide properties.

\section{MATERIALS AND METHODS}

Parasites - We used stationary-phase cultured promastigotes of L. (Viannia) braziliensis (MHOM/ BR/95DCB-22), amastigotes of $L$. (L.) amazonesis (MCAN/BR/94DCB-16) and L. (L.) chagasi (MHOM/BR/95/DCB-27).

Macrophages - Macrophages were obtained from healthy adult male and female mongrol dogs kept at the Jorge Waistman Institute of Veterinary Medicine, under the Rio de Janeiro Health Secretariat. The health of the animals was established on 
the basis of results of a clinical examination and the evaluation for antibodies to Leishmania using the indirect immunofluorescence reaction. The dogs had their peritoneal cavity washed four days after stimulation with Sephadex G50 (Pharmacia) at a concentration of $70 \mathrm{mg} / \mathrm{kg}$ body weight.

Dogs were anesthetized with an intravenous injection of sodium pentobarbital (Ceme, Brazil) at $25 \mathrm{mg} / \mathrm{kg}$ body weight. The peritoneal cavity was washed with a $500 \mathrm{ml}$ volume of $0.85 \%$ physiological saline solution containing $0.3 \%$ sodium citrate, $100 \mathrm{U}$ penicillin, and $100 \mu \mathrm{g}$ streptomycin $/ \mathrm{ml}$. Approximately $80 \%$ of the lavage fluid was recovered, packed at $4^{\circ} \mathrm{C}$, and immediately processed.

Isolation and infection of macrophages - The lavage fluid was concentrated by centrifugation at $800 \mathrm{~g}$ for $10 \mathrm{~min}$ at $4^{\circ} \mathrm{C}$ and resuspended in RPMI1640 containing $100 \mathrm{U}$ penicillin and $50 \mu \mathrm{g}$ streptomycin $/ \mathrm{ml}$. Cell viability was determined using $0.2 \%$ trypan blue exclusion dye (Phillips 1973) and adjusted to give a cell density of $2 \times 10^{6}$ per ml, using a Neubauer hemocytometer in RPMI-1640 medium without serum.

Each milliliter of cell suspension was placed in a test tube (Vidrolabor $15 \mathrm{~cm} \times 10 \mathrm{~cm}$ ) containing a coverslip. The tubes were incubated at $35^{\circ} \mathrm{C}$ for 2 $3 \mathrm{hr}$. There after, the medium was removed and each tube was washed with RPMI-1640 medium to remove the non-adherent cells. After washing, RPMI-1640 was added, containing antibiotics and $10 \%$ sterile inactivated homologous canine serum.

After $24 \mathrm{hr}$ in dishes, the cell monolayers were infected at a ratio of 5-10 parasites per host cell with incubation at $35^{\circ} \mathrm{C}$ when the infection was with $L$. (L.) amazonensis and $L$. (L.) chagasi and $34^{\circ} \mathrm{C}$ when the infection was by $L$. (V.) braziliensis for a period of 2-3 hr. After this period, the cell monolayers were washed, complete RPMI was added, and the respective temperatures were maintained. At $24 \mathrm{hr}$ intervals the coverslips were washed in PBS, fixed in methanol, and stained with Giemsa. The percentage of infected cells was determined by individual counts on the slide covers under light microscopy, making a total of 100 cells.

\section{RESULTS}

The results of this investigation, as shown in Fig. 1, indicate that $24 \mathrm{hr}$ after infection the percentage of infected cells were $81 \%$ for $L$. $(V$.) braziliensis, $67 \%$ for $L$. (L.) amazonensis, and $90 \%$ for $L$. $(L$.) chagasi. These values incresead over the course of the study and by the sixth day postinfection they stood at $92 \%, 95 \%$, and $98 \%$ of infected cells, respectively.

Fig. 2 shows peritoneal macrophages infected with $L$. (V.) braziliensis, $L$. (L.) amazonensis and $L$. (L.) chagasi at 3, 5 and 6 day post-infection re-

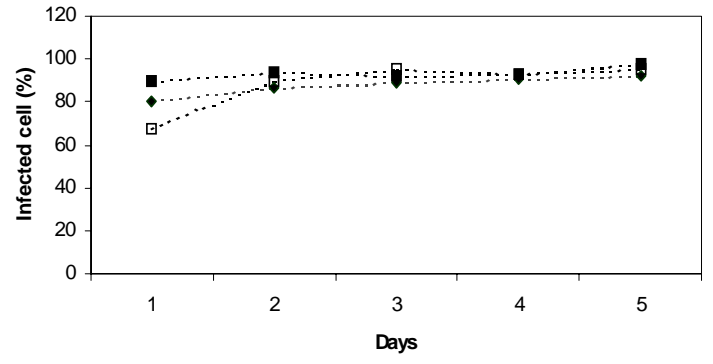

Fig. 1: the percentage of cells infected with Leishmania (Viannia) braziliensis ( --- ), L. (L.) amazonensis ( --- ) and $L$. (L.) chagasi ( --- ) with mean of two experiments during six days of observation.

spectively. At least two different patterns of infection were observed during the experiment on macrophages infected by each Leishmania specie. The aspect of cells parasited with $L$. $(L$.) amazonensis is typical providing the appearance of many vacuoles. By the way on the two others epecies the parasite multiplication is closer.

\section{DISCUSSION}

The use of canine peritoneal macrophages for in vitro studies has been sparsely documented, although different cell lines have been used experimentally in various investigations, displaying advantages and disadvantages (Mattock \& Peters 1975, Chang 1980, Berman \& Wyler 1980).

To our knowledge this is the first report concerning the utilization of canine peritoneal macrophages experimentally infected with three species of Leishmania, since the literature only includes utilization of these cells in association with infection by Ehrlichia canis (Nyindo et al. 1971, Stephenson \& Osterman 1977). Lack of utilization of this in vitro cellular model may be resultant from the inherent difficulties associated with keeping larger animals as compared to smaller rodents.

The specific purposes of this investigation led us to develop a relatively simple technique for washing the peritoneal cavity of dogs, providing up to $10^{9}$ cells on total volume, while utilization of special cannulae in this procedure (Zeman \& Neri 1970) eliminates the need to sacrifice the animals.

In our study, the characteristics displayed by the cells cultured in vitro were similar to those described elsewhere, presenting single spherical and kidney-shaped nuclei located excentrically in the cell (Stephenson \& Osterman 1977). However, in some cases there was not a good spreading of the cells, which may be linked to biological factors includind state of cell maturation and age and sex of the donor animals, factors which cannot be controlled by our methodology. 

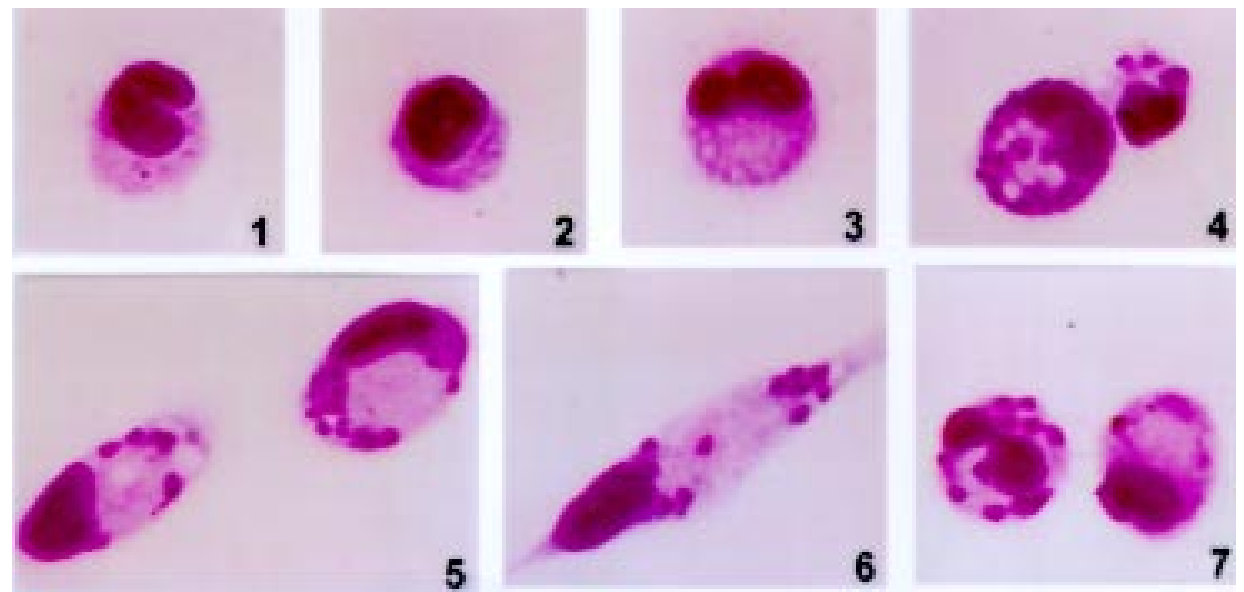

5
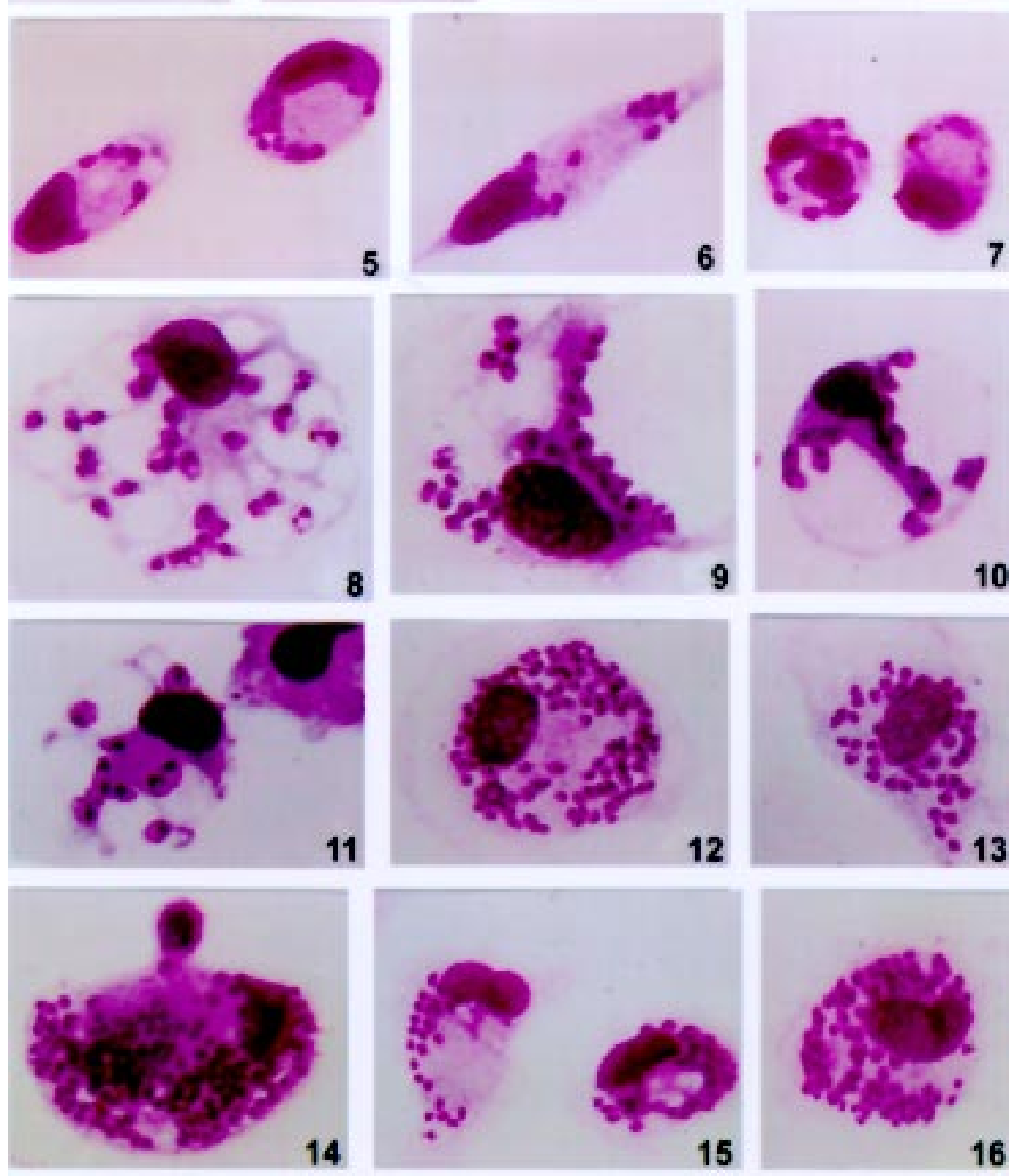

Fig. 2: photomicrograph of canine peritoneal macrophages cultured in vitro (Giemsa stain; x 1000). Figs 1-3: normal (non-infected) macrophages. Figs 4-7: macrophages infected with Leishmania (Viannia) braziliensis. Figs 8-11: macrophages infected with $L$. (L.) amazonensis. Figs 12-16: macrophages infected with $L$. $(L$.) chagasi. 
Numerous reports on the evaluation of the in vitro multiplication of different Leishmania species suggest a correlation with the in vivo system, e.g., where it is possible to observe the limited capacity of $L$. (V.) braziliensis to grow in murine macrophages, while L. amazonensis displays exuberant multiplication in this cell type (Zeledón et al. 1969, Grimaldi Jr et al. 1983).

Actually the utilization of the two forms, amastigotes and viable promastigotes, could be a start and to follow up the macrophage infection by Leishmania (Berman \& Lee 1984). In this study it was used to infect the canine cells a pool of metacyclic and non-metacyclic promastigotes harvested from stationary phase culture of $L .(V$.) braziliensis and amastigotes of $L$. (L.) amazonensis and $L$. $(L$.) chagasi and the three species clearly behaved differently with regard to their multiplication rate. The $L$. $(L$.) chagasi displayed greater capacity for multiplication than the two others (data not show).

So in order to make sure if the macrophage infection by $L$. $(L$.) chagasi really display greater affinity for canine cells as seen in this study a specific experiment is being performed with only Leishmania metaciclic promastigotes forms.

Our results support the hypothesis that these three organisms behave differently, both in their morphology and location in the host cell, showing characteristic patterns and the formation of large vacuoles as observed in the murine cells infected by $L$. (L.) amazonensis (Grimaldi Jr et al. 1983).

In addition the standartization of this efficacious system open perspectives to study the role of this animal as an important reservoir for both visceral and mucocutaneous leishmaniasis by $L$. $(V$.) braziliensis, besides the evaluation of new efficient drugs and/or natural products with potential leishmanicide activity.

\section{ACKNOWLEDGEMENTS}

To Roger Magno Macedo Silva for technical assistance.

\section{REFERENCES}

Barbosa-Santos EGO, Marzochi MCA, Urtado W, Queirós F, Pacheco RS, Chicarino J 1994. Immunotherapy and chemotherapy of mucocutaneous and disseminated cutaneous leishmaniasis in a horse in Brazil. Mem Inst Oswaldo Cruz 89: 217.

Berman JD 1985. Experimental chemotherapy of leishmaniasis - A critical review, p. 112-138. In KP Chang \& RS Bray (eds), Leishmmaniasis, Elselvier Science Publishers B. V., Amsterdam, New York, Oxford.

Berman JD, Lee LS 1984. Activity of antileishmanial agents against amastigotes in human monocyte-derived macrophages and in mouse peritoneal macrophages. J Parasitol 70: 220-225.

Berman JD, Wyler DJ 1980. An in vitro model for in- vestigation of chemotherapeutic agents in leishmaniasis. J Infect Dis 142: 83-86.

Carrel A, Ebeling AH 1922. Pure cultures of large mononuclear leucocytes. J Exp Med 36: 365-377.

Chang KP 1980. Human cutaneous Leishmania in a mouse macrophage line: propagation and isolation of intracellular parasites. Science 209: 1240-1242.

Chapman WL, Hanson WL, Waits VB, Kinnamon KE 1979. Antileishmanial activity of selected compounds in dogs experimentally infected with Leishmania donovani. Rev Inst Med Trop São Paulo 21: 189-193.

Grimaldi Jr G 1982. Leishmanioses tegumentares: aspectos clínicos e imunopatológicos. Mem Inst Oswaldo Cruz 77: 195-215.

Grimaldi Jr G, Côrte-Real S, Pinho RT, Moriarty PL 1983. Interactions between Leishmania mexicana mexicana promastigotes and amastigotes and murine macrophages in vitro. Mem Inst Oswaldo Cruz 78: $135-146$.

Lopes UG, Momen H, Grimaldi Jr G, Marzochi MCA, Pacheco RS, Morel CM 1984. Schizodeme and zymodeme characterization of Leishmania in the investigation of foci of visceral and cutaneous leishmaniasis. J Parasitol 70: 89-98.

Marzochi MCA 1992. Leishmanioses no Brasil. As leishmanioses tegumentares. J Bras Med 63: 82-104.

Marzochi MCA, Marzochi KBF 1994. Tegumentary and visceral leishmaniases in Brazil - Emerging anthropozoonosis and possibilities for their control. Cad Saúde Púb 10: 359-375.

Mattock NM, Peters W 1975. The experimental chemoterapy of leishmaniasis. I - Techniques for the study of drug action in tissue culture. Ann Trop Med Parasitol 69: 349-357.

Nyindo MBA, Ristic M, Huxsoll DL, Smith AR 1971. Tropical canine pancytopenia: in vitro cultivation of the causative agents - Ehrlichia canis. Am J Vet Res 32: 1651-1655.

Pacheco RS, Lopes UG, Morel CM, Grimaldi Jr G, Momen H 1986. Schizodeme analysis of Leishmania isolates and comparison with some phenotypic techniques, p. 57-65. In Leishmania Taxonomie et Phylogenèse. Applications Eco-épidémiologiques, IMEEE, Montpellier.

Phillips HJ 1973. Dye exclusion test for cell viability, p. 406-408. In PF Kruse Jr \& MK Patterson Jr (eds), Tissue Culture Methods and Applications, Academic Press, New York.

Pirmez C, Marzochi MCA, Coutinho SG 1988. Experimental canine mucocutaneous leishmaniasis (Leishmania braziliensis braziliensis). Mem Inst Oswaldo Cruz 83: 145-151.

Stephenson FH, Osterman JV 1977. Canine peritoneal macrophages: cultivation and infection with Ehrlichia canis. Am J Vet Res 38: 1815-1819.

Zeledón R, Blanco E, De Monge E 1969. Comparative experimental infections with Costa Rican strains of Leishmania braziliensis Vianna, 1911. Acta Trop 26: 136-155.

Zeman WV, Neri RO 1970. Permanent access to the peritoneal cavity in dogs: a method for massive leukocyte withdrawal. Am J Vet Res 31: 1297-1301. 